\title{
Hemşirelik Öğrencilerinde Girişimcilik Düzeyi ve Etkileyen Faktörlerin Belirlenmesi
}

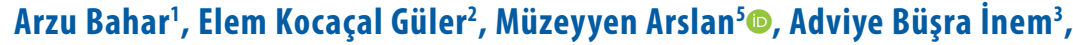 \\ Zehra Seda Çimen ${ }^{4}$
}

${ }^{1}$ Girne Amerikan Üniversitesi, Hemşirelik, Girne, Kuzey Kıbrıs TC 2̇stanbul Kent Üniversitesi, Hemşirelik, İstanbul, Türkiye ${ }^{3}$ Lösante Çocuk ve Yetişkin Hastanesi, Hemşirelik, Ankara, Türkiye ${ }^{4}$ Beykoz Devlet Hastanesi, Hemşirelik, İstanbul, Türkiye

${ }^{5}$ Her hangi bir kurumda çalışmamaktadır., Hemşirelik, Ankara, Türkiye

Arzu Bahar, Yrd. Doç. Dr. Elem Kocaçal Güler, Dr. Öğr. Üyesi Müzeyyen Arslan, Dr. Öğr. Üyesi Adviye Büşra İnem, Uzm. Hemş. Zehra Seda Çimen, Uzm. Hemş.

İletişim:

Yrd. Doç. Dr. Arzu Bahar

Girne Amerikan Üniversitesi, Hemşirelik, Girne, Kuzey Kibris TC

Tel: +903926502000

E-Posta: arzbahar@gmail.com
ÖZET

Amaç: Bu tanımlayıı çalışmanın amacı, hemşirelik öğrencilerinde girişimcilik düzeyinin ve bu düzeyi etkileyen faktörlerin belirlenmesidir.

Yöntem: Araştırmanın örneklemi, 2014-2015 öğrenim yılında, Ankara'da bir üniversitenin hemşirelik yüksekokulunda öğrenim gören ve çalışmaya katılmayı kabul eden 178 öğrencidir. Veriler Kişisel Bilgi Formu ve Üniversite Öğrencileri Girişimcilik Ölçeği kullanılarak toplanmıştır. Verilerin analizinde tanımlayıcı istatistikler (Ortalama ve standart sapma), Wilcoxon İ̧saretli Sıra Testi, Mann-Whitney U, Kruskal-Wallis ve Dunn's Testi kullanılmıştır.

Bulgular: Araştırmaya katılan öğrencilerin yaş ortalaması $21 \pm 2.6$ yıl olup, $\% 28$ i birinci sınıf, \%32'si ikinci sınıf, $\% 23$ 'ü üçüncü sınıfta ve \%27'si dördüncü sınıfta öğrenim görmektedir. Öğrencilerin girişimcilik toplam puan ortalaması 136.78 \pm 1.68 olup girişimcilik düzeyi yüksek olarak bulunmuştur. Öğrencilerin bir işte çalışma deneyimi, girişimci bir yakının olma ve lider kişilik özelliğine sahip olma durumu ile girişimcilik düzeyi toplam puan ortalamaları arasında istatistiksel olarak anlamlı bir fark bulunmuştur $(p<0.05)$.

Sonuç: Hemşire öğrencilerin girişimcilik düzeyleri yüksek oranda bulunurken, bu özelliklerinin ön plana çıkarılması ve güçlendirilmesi gerekmektedir.

Anahtar sözcükler: girişimcilik, hemşirelik, öğrenci

\section{DETERMINATION OF ENTREPRENURSHIP LEVEL AND AFFECTING FACTORS IN NURSING STUDENTS}

\section{ABSTRACT}

Purpose: The aim of this descriptive study is to determine the level of entrepreneuship and related factors in nursing students.

Methods: The study sample consisted of 178 students in a nursing school at a university in Ankara who received education in 2014-2015 academic year and agreed to participate in the study. The data were collected through the Personel Information Form and University Student Entreprenurship Scale (USES). Descriptive statistics (mean and standard deviation), Wilcoxon Signed Rank test, Mann-Whitney U test, Kruskal-Wallis test and Dunn's test were used in analyzing the data.

Results: The mean age of the students who participated in the study was $21 \pm 2.6$ years. $28 \%$ of those students were in the first year, $32 \%$ were in the second year, $23 \%$ were in the third year and $27 \%$ were in the fourth year. The mean score for the students on the University Student Entreprenurship Scale (USES) was $136.78 \pm 1.68$ point as to be considered a high level entrepreneurship. There was a statistically significant difference $(p<0.05)$ among having a work experience, having entrepreneur relatives, entrepreneural personality and a level of entrepreneurship.

Conclusions: The entrepreneurship level in nursing students was found to be high. These characteristics need to be highlighted and strengthened.

Keywords: entrepreneurship, nursing, student
Gönderilme Tarihi : 19 Eylül 2017

Revizyon Tarihi : 260cak 2018

Kabul Tarihi : : 310cak 2018 
ünümüzde bilim, teknoloji, ekonomi alanında yaşanan gelişmeler ve istihdamı arttırmak için yapılan çalışmalar göz önünde alındığında, yaşam kalitesini arttırmaya yönelik faaliyetleri içinde barındıran girişimcilik kavramı çağımızın yükselen bir değeridir (1).

Girişimcilik, genel anlamıyla yeni yüzyılda risk alma, yenilikleri yakalama, fırsatları değerlendirme ve tüm bunların hayata geçirilme süreci olarak tanımlanmaktadır. Girişimciliğin bir öğesi olan girişimci; kaynakları, iş gücünü, materyalleri ve diğer öğeleri bir araya getiren, bunlara önceki değerlerinden daha fazla değer katan, bir anlamda ülkenin ekonomik anlamda dinamosu işlevini üstlenen kişidir $(2,3)$.

Tüm Dünya'da hızla artan nüfus nedeniyle sağlık sektörü, sağlık hizmetlerinin sunumunda değişikliğine gitmiş ve bu hizmetleri direkt vermek yerine, özel sektörden bu hizmetleri kiralayarak ulaştırmaya çalışmıştır (4). Bu durum ise, bu hizmetleri verebilecek olan hemşirelerin sağlık hizmet sektöründe yer alabilmek için kendi işini kurmasına olanak sağlamıştır (5). Sağlık sektöründe bireysel iş sahibi olan hemşire sayılarının artmasıyla beraber, Dünya'daki en büyük hemşirelik birliği olan Uluslar arası Hemşirelik Birliği (ICN), 2014 yılında girişimci hemşirelik rehberini yayımlamıştır. Bu rehbere göre; girişimci hemşire, sağlık hizmetleri danışmanlığı, sağlık bakım ürünlerinin geliştirilmesi, pazarlaması ve yönetimi ile yaşlı bakımı, yara bakımı ya da doğrudan hemşirelik hizmetlerinin sunumunda işveren olan hemşireler olarak tanımlanmıştır (6).

Girişimci hemşireler, sağlık alanında bu hizmetleri yerine getirebilecek hemşirelerin istihdamını sağlar $(6,7)$. Hemşirelik mesleğinde girişimciliğin eskilere dayanması ve birçok ülkede kadın girişimcilerin devlet tarafından desteklenmesine rağmen; hemşirelerin sadece $\% 0.5-1$ 'nin girişimci kişiler olarak hayatlarını sürdürdükleri bildirilmiştir $(6,8)$.

Yapılan çalışmalarda bu oranın düşük olmasına, yüksek sigorta maliyetleri, malpraktis durumlarında ödenen tazminatlarının yüksekliği, hemşirelik eğitim müfredatının bu beceriyi edindirecek şekilde düzenlenmemiş olması, iş planı yazma bilgisinin eksikliği, ofis yönetim becerisindeki yetersizlikler ve diğer disiplinlerle çalışmada ortaya çıkan sorunların yol açtığı belirtilmiştir $(8,9)$. Çalışma sonuçlarıyla ortaya konan tüm bu sorunlara karşın girişimci olarak çalışan hemşireler, hastanelerdeki iş yükünün fazla olması, kendi işine sahip olma, bağımsız çalışabilme, çaIışma programını düzenleyebilme gibi nedenlerle kendi işini kurma gereksinimi duyduklarını ifade etmiştir (10). Girişimci olan hemşireler, girişimcilik konusunda istekli olan meslektaşlarına, etkili iletişim kurabilme, kritik düşünebilme, işbirliği yapabilme becerilerinin yanında yenilikçi ve sabırlı kişilik özelliklerine sahip olmaları gerektiğini önermektedir $(5,8,11)$.

Girişimciliğin ülkelerin ekonomik ve sosyal alanlarda sağladığı katkıların yanında mesleki gelişime kazandırdığı değerler göz önüne alındığında, üniversitelerde girişimcilik eğiliminin arttırılması akademik çalışmaların hedefi olmasının yanında, önemli bir sosyal sorumluluk olarak karşımıza çıkmaktadır (11). Hemşirelikte girişimcilikle ilgili çalışmalar incelendiğinde, birçoğunun girişimcilikte başarı arttırmaya yönelik rehberler, girişimciliği engelleyen sorunlar, girişimciliği etkileyen faktörler, girişimci hemşirelerin yaşadıkları sorunları ortaya koyan daha çok niteliksel çalışmalar olduğu görülmektedir.

Konu ile ilgili literatür incelendiğinde, değişen hemşirelik müfredatında yer alan sosyal girişimcilik derslerinin verilmesine rağmen hemşirelik öğrencilerinin girişimcilik ilgisi ve becerisi işletme ve mühendislik öğrencileri kadar istendik düzeyde değildir (12). Üniversite öğrencileri ile yapılan çalışmalarda, işletme, eğitim bilimleri, sağlık yönetimi öğrencilerinin girişimcilik eğilimini gösteren çalışmalar bulunmasına karşın, geleceğin hemşireleri olacak öğrenci hemşirelerin girişimcilik potansiyellerini gösteren girişimcilik düzey ve eğilimlerini belirleyen çalışmaların oldukça sınırlı sayıda olduğu görülmüştür (8). Bu nedenle bu konuya açıklık getiren çalışmaların yapılması önem arz etmektedir. Bu araştırma, hemşirelik öğrencilerinde girişimcilik düzeyinin ve öğrencilerin sosyo-demografik ve bazı kişisel özellikleri ile girişimcilik düzeyleri arasındaki ilişkinin incelenmesi amacıyla tanımlayıcı olarak yapılmıştır.

\section{Gereç ve yöntem}

Bu araştırma, Ankara'da bir üniversitenin hemşirelik yüksekokulunda öğrenim gören öğrencilerde tanımlayıcı türde gerçekleştirilmiştir.

Araştırmada örneklem seçimine gidilmeyerek 2014-2015 yılları arasında öğrenim gören, tüm evreni oluşturan 223 hemşirelik öğrencisi hedeflenmiş, ancak ulaşılamayan, araştırmaya katılmayı kabul etmeyen ve formları tam olarak tamamlamayan öğrenciler nedeniyle, 178 öğrenciye (kapsayıcılık oranı \%80) ulaşıımıştır.

Araştırma verileri 01 Mart-15 Nisan 2015 tarihleri arasında toplanmıştır. Gönüllü olarak çalışmaya katılan öğrencilerin, kendi öz bildirimlerine dayalı olarak Kişisel Bilgi Formu ve Üniversite Öğrencileri Girişimcilik Ölçeği'ni (ÜÖGÖ) 
doldurmaları sağlanmıştır. Formlar öğrencilerin birbiri ile etkileşimini önlemek için aynı zamanda, sınıf ortamında uygulanmıştır. Formların doldurulması yaklaşık 25 dakika sürmüştür.

Kişisel Bilgi Formu: Araştırmacılar tarafından ilgili literatür doğrultusunda geliştirilen bu form, araştırmaya katılan öğrencilerin yaş, cinsiyet, gelir durumu gibi sosyo-demografik özellikleri ile girişimciliği etkileyecek faktörleri belirten toplam 14 sorudan oluşmaktadır. Bu formun anlaşırlığı açısından üç akademisyen hemşirenin uzman görüşüne başvurulmuştur.

\section{Üniversite Öğrencileri Girişimcilik Ölçeği (ÜÖGÖ):}

Yılmaz ve Sümbül (2009) tarafından üniversite öğrencilerinin girişimciliklerinin değerlendirilebilmesi için geliştirilmiştir. Toplam 36 maddeden oluşan ölçekte sorular eşit aralıklı 5'li Likert tipine göre düzenlenmiştir. Bu ölçeğe göre cevap verenlerin ifadelere katılma düzeyleri, $1=$ kesinlikle katılmıyorum, 2=büyük oranda katılmıyorum, 3=kısmen katılıyorum, 4=büyük oranda katılıyorum, 5=kesinlikle katılıyorum şeklinde ölçeklendirilmiştir. Araştırmacılar ölçeğin Cronbach alfa güvenirlik katsayısını 0.90 olarak bulmuştur. Her maddenin aritmetik ortalaması ve genel aritmetik ortalama hesaplanmış ölçekte, aritmetik ortalama 36 ile çarpılarak bulunmuştur. Üniversite öğrencileri girişimcilik ölçeği puan kategorileri; çok düşük girişimcilik (36-40 puan), düşük girişimcilik (65-92 puan), orta düzeyde girişimcilik (93123 puan), yüksek girişimcilik (124-151 puan), çok yüksek girişimcilik (152-180 puan) olarak sınıflanmaktadır (2).

Verilerin toplanmasından önce, Üniversite Öğrencileri Girişimcilik Ölçeği'ni geliştiren yazarlardan ölçeğin çalışmada kullanılabilmesi için elektronik posta yolu ile yazılı izin alınmıştır. Daha sonra araştırmanın yapılabilmesi için ilgili üniversitenin Klinik Araştırmalar Etik Kurulu'ndan gerekli izinler alınmıştır. Çalışmaya katılan öğrencilerden araştırma hakkında bilgi verildikten sonra, yazılı onam alınmıştır. Araştırmaya katılan öğrencilere araştırma raporunda kişisel bilgilerin yer almayacağı ve isimlerinin gizli tutulacağı bildirilmiştir.

Çalışmadan elde edilen verilerin analizi, SPSS 21.0 paket programında yapılmıştır. Araştırmadan elde edilen verilerin istatistiksel değerlendirmesinde sayı, yüzdelik, Wilcoxon İşaretli Sıra Testi, Mann-Whitney (U) Testi, Kruskal-Wallis Testi ve çoklu karşılaştırma yöntemi olarak Dunn's Testi kullanılmıştır. Araştırmada tüm bulgular \%95 güven aralığında, anlamlılık $p<0.05$ düzeyinde değerlendirilmiştir.

\section{Bulgular}

Araştırmaya katılan öğrencilerin yaş ortalamasının $21 \pm 2.6$ (Min:18, Max:35) yıl olup, \%87.1'inin kız ve \%21.3'ünün sağlık meslek lisesi mezunu olduğu ve \%28'inin birinci, \%32'sinin ikinci, \%23'ünün üçüncü ve \%27'sinin dördüncü sınıfta öğrenim gördüğü saptanmıştır. Öğrencilerin \%41.6'sı akademik ortalamasının "2.5 ve üzerinde" olduğunu, \%60.1'i ise; orta düzeyde İngilizce bildiğini ifade etmiş̧ir.

Öğrencilerin \%26.4'ünün girişimcilik dersi aldığı, \%43.3'ünün ise; bir işte çalışma deneyimi olduğu belirlenirken, \%55.1'i ailesinde kendi işini kuran bir girişimci yakınının olduğunu bildirmiştir. Başarılı bir girişimcide var olan özelliklerden hangisine daha çok sahip oldukları sorusuna öğrencilerin \%30.3'ü dürüstlük, \%29.2'si iyi bir iletişimci özelliklerine sahip olması gerektiğini bildirmiştir (bu bulguların tablosu sunulmamıştır).

Hemşirelik öğrencilerinin Üniversite Öğrencileri Girişimcilik Ölçeği'nden elde edilen girişimcilik puanı ortalaması $136.78 \pm 1.68$ puan olarak bulunmuştur. Öğrencilerin \%23.6'sı çok yüksek düzeyde girişimci, $\% 50.6$ 'sı yüksek düzeyde girişimci, \%19.8'i orta düzeyde girişimci, \%5.1'i düşük düzeyde girişimci olarak belirlenmiş, çok düşük düzeyde girişimci özelliği olan öğrenci oranının ise $\% 0.9$ olduğu bulunmuştur (Tablo 1 ).

Tablo 1. Öğrencilerin girişimcilik düzeylerinin dağllımı $(n=178)$

Girişimcilik ölçeği toplam puan ortalaması X+SS (Min-Max): $136,78 \pm 1,68$ (49-178)

\begin{tabular}{lcc}
\hline Girişimcilik düzeyi & $\boldsymbol{n}$ & $\%$ \\
\hline Çok düşük & 2 & 0.9 \\
Düşük & 9 & 5.1 \\
Orta & 35 & 19.8 \\
Yüksek & 90 & 50.6 \\
Çok yüksek & 42 & 23.6 \\
Toplam & 178 & 100.0
\end{tabular}

Çalışmaya katılan öğrencilerin girişimcilik puan ortalamaları ile yaş, cinsiyet, gelir düzeyi, kalınan yer, anne ve babanın eğitim durumu, mezun olunan okul, akademik başarı puanı, yabancı dil düzeyi ve girişimcilik dersi alma durumu arasında anlamlı bir fark bulunmamıştır ( $p>0.05$ ). Bir işte çalışma deneyimi, öğrencilerin ailelerinde kendi işini kuran girişimci birinin olma durumu ve girişimci kişilik özelliklerine sahip olma durumu ile girişimcilik puan ortalaması arasında anlamlı fark olduğu bulunmuştur $(p<0.05)$. Kendini pratik düşünebilme becerisine sahip olarak gören öğrencilerin girişimcilik puan ortalaması $132.47 \pm 23.81$, 
lider olarak tanımlayanların girişimcilik puan ortalaması ise $146.06 \pm 31.42$ olarak bulunmuştur. Yapılan ileri analiz Bonferoni düzeltmesinde aradaki istatistiksel anlamlılığın liderlik becerisine sahip olduğunu düşünen öğrencilerden kaynakladığı belirlenmiştir (Tablo 2).

Tablo 2. Öğrencilerin tanıtıcı özelliklerine göre girişimcilik puan ortalamalarının karşılaştırıması $(n=178)$

\begin{tabular}{|c|c|c|c|c|}
\hline & $x$ & $\pm S S$ & $p$ & $z$ \\
\hline \multicolumn{5}{|l|}{ Yaş grubu } \\
\hline $18-24$ & 134.57 & 23.18 & 0.377 & 2.78 \\
\hline $25-29$ & 136.28 & 39.67 & & \\
\hline 30 Ve Üzeri & 119.82 & 26.72 & & \\
\hline \multicolumn{5}{|l|}{ Cinsiyet } \\
\hline $\mathrm{K} \mathrm{Iz}$ & 135.03 & 24.24 & 0.18 & -1.325 \\
\hline Erkek & 128.78 & 22.18 & & \\
\hline \multicolumn{5}{|c|}{ Bir İşte Çalışma Deneyimi } \\
\hline Evet & 142.98 & 22.85 & $0.02^{\star}$ & 1.25 \\
\hline Hayır & 131.39 & 24.59 & & \\
\hline \multicolumn{5}{|c|}{ Girişimcilik Dersini Alma } \\
\hline Evet & 133.21 & 24.73 & 0.59 & -0.53 \\
\hline Hayır & 134.59 & 23.83 & & \\
\hline \multicolumn{5}{|l|}{$\begin{array}{l}\text { Ailede Girişimci Bir } \\
\text { Yakının Olması }\end{array}$} \\
\hline Evet & 138.16 & 21.82 & $0.01 *$ & 2.48 \\
\hline Hayır & 129.45 & 25.79 & & \\
\hline \multicolumn{5}{|c|}{$\begin{array}{l}\text { Girişimci Kişilik } \\
\text { Özelliklerine Sahip Olma }\end{array}$} \\
\hline $\begin{array}{l}\text { Pratik düşünebilme } \\
\text { becerisi }\end{array}$ & 132.47 & 23.81 & $0.04^{*}$ & 3.25 \\
\hline Çalışkanlık & 132.52 & 21.43 & & \\
\hline Dürüstlük & 131.9 & 28.12 & & \\
\hline Liderlik & 146.06 & 31.42 & & \\
\hline $\begin{array}{l}\text { Bağımsıı çalışabilme } \\
\text { becerisi }\end{array}$ & 133.76 & 26.13 & & \\
\hline İyi Iletişim becerisi & 129.86 & 24.53 & & \\
\hline
\end{tabular}

\section{Tartışma}

Bu araştırma sonucunda; hemşirelerin girişimcilik düzeyinin yüksek olduğu ve çalışma deneyimi, kişilik özellikleri ve ailede kendi işini kuran birinin bulunmasının öğrencilerin girişimciliği üzerinde etkili olduğu bulunmuştur.

Araştırma sonucuna göre; araştırmaya katılan hemşirelik öğrencileri "yüksek girişimcilik" eğilimi göstermektedir. Üniversite öğrencilerinin girişimcilik eğilimlerinin ölçüldüğü benzer çalışma sonuçları incelendiğinde, Gemlik ve ark.'nın (2013) öğrencilerde yürüttüğü çalışmada girişimcilik ölçeği puan ortalaması 139.99 puan "yüksek düzeyde" olarak belirlenirken (13), sağlık yönetimi bölümü öğrencilerinde yapılan bir başka çalışmada öğrencilerinin girişimcilik puan ortalaması 143.88 puan olarak bulunmuştur (4). Çalışmamızla paralel olan bu bulgular, öğrencilerin girişimcilik düzeyinin yüksek ve orta düzeyde olduğunu ve kendilerinde girişimcilik potansiyelinin var olduğu düşüncesine sahip olduklarını göstermektedir $(2,4,14,15)$. Bu sonuçların aksine; Roncon ve Munhoz (2009) tarafından Portekiz'de 41 hemşirelik öğrencisi ile genel girişimcilik anketi ile verilerin toplandığı çalışma sonucunda, öğrencilerin \%80'inin girişimci kişilik profiline uymadığı ve girişimcilik eğiliminin olmadığı, sadece \%14'ünün girişimci kişilik özellikleri taşıdığı bildirilmiştir (16). Bu uyumsuzluk, öğrencilerin kişilik özelliklerinin yanı sıra, iki ülkedeki eğitim sisteminin farklılığından kaynaklanmış olabilir.

Sonuçlarımıza göre; öğrencilerin cinsiyeti ve girişimcilik düzeyleri arasındaki ilişki incelendiğinde, istatistiksel olarak anlamlı bir fark olmadığı saptanmıştır (Tablo 2). Cinsiyet ve girişimcilik düzeyi arasındaki ilişkinin araştıııldığı çalışmalarda sonuçların çeşitlilik gösterdiği görülmektedir $(5,15,17-$ 19). Öztürk ve ark.'nın (2014) sağlık bölümü öğrencileriyle yaptığı çalışmada da, bulgularımızla paralel olarak, girişimcilik eğilimleri ile cinsiyet arasında bir ilişki olmadığı belirlenmiştir (4). Girişimcilikle cinsiyet arasında fark olmaması, kadınların toplumsal olarak gelenekselleşmiş rollerinden çıkarak toplumda daha fazla söz sahibi olmak istemesi, kadın erkek fırsat eşitsizliğinin giderek azalması, bazı sivil ve kamu kurumları tarafından girişimci kadınlara sağlanan finansal desteğin artışı ile ilişkili olabilir. Bu bulguların aksine; Singapurlu üniversite öğrencileri ve Amerikalı gençler ile yürütülen iki ayrı çalışmada; erkek öğrencilerin kız öğrencilere göre daha fazla girişimcilik eğilimi gösterdiği saptanmıştır $(18,19)$. Solmaz ve ark.'nın (2014) yürüttüğü araştırmada ise; kız öğrencilerin daha yüksek girişimcilik düzeyine sahip olduğu saptanmıştır (15).

Araştırmamız sonucunda, okul dışında her hangi bir işte çalışma deneyimi ile girişimcilik düzeyi arasında istatistiksel olarak anlamlı bir fark bulunmuştur (Tablo 2). Keleş ve ark. (2012) tarafından yapılan çalışmada da bulgularımızla uyumlu olarak iş deneyimi olan öğrencilerin diğerlerine göre daha girişimci oldukları ortaya konmuştur (20). Bu sonuçlar doğrultusunda, bir işte çalışarak kazanılan olumlu yaşantı ve deneyimlerin öğrencileri iş dünyasına özendirdiği ve girişimcilik düzeylerini arttırdığı söylenebilir.

Sonuçlarımıza göre; ailede girişimci olarak kendi işini kuran birinin olması ile girişimcilik düzeyi arasındaki fark istatistiksel olarak anlamlı bulunmuştur (Tablo 2). Bu 
konuyu inceleyen diğer çalışmalar gözden geçirildiğinde kısmen farklı sonuçlar elde edildiği görülmektedir (13,2022). Türk Iş Adamları Derneği'nin (TÜSIAD) 2002'de yayımladığı rapor ve Can (2014), Doğaner (2010) ile Özden ve ark.'nın (2008) yürüttükleri çalışmalarda aileleri başarılı bir girişimcilik süreci geçirmiş olan öğrencilerin de girişimciliğe ilgi ve eğiliminin arttığı bildirilmiştir $(17,21,23,24)$. Araştırmamızla uyumluluk gösteren bu sonuçlardan yola çıkarak, girişimciliğin doğuştan bir yetenek olmadığı, insanın en temel sosyal bir kurum olan ailede girişimcilik örneğinin olmasının öğrencilerde girişimciliği desteklediği söylenebilir.

Çalışma sonuçlarımıza göre, öğrencilere teorik ağırlıklı olarak girişimcilik dersi adıyla verilen girişimcilik eğitimi ile girişimcilik eğilimleri arasında istatistiksel olarak anlamlı bir fark görülmemiş̧ir (Tablo 2). Araştırma sonuçlarımızla paralellik gösteren Uluyol'un (2013) çalışmasında finansal yönetim ve girişimcilik dersi alan meslek yüksekokulu öğrencilerinin girişimcilik eğilimleri arasında fark olmadığı bulunmuştur (25). Konu ile ilgili diğer çalışmaların sonuçları incelendiğinde, eğitimin gerekli olduğu, kısmen de olsa girişimcilik becerisini arttırdığı fakat tek başına yeterli olmadığı belirtilmektedir $(18,26)$. Bu sonuçlar dikkate alındığında girişimciliğin bir beceri olduğu, sadece eğitimle kazanılamayacağı, ancak girişimciliğe eğilimi olan bireylere uygun eğitim olanakları sağlandığında eğitimin daha etkin olacağı düşünülmektedir.

Sonuçlarımıza göre; kişilik özellikleri ile girişimcilik düzeyi arasında anlamlı bir fark olduğu bulunmuştur (Tablo 2). Ayrıca öğrenciler girişimci kişilik özelliklerinden en çok liderlik ve iyi bir iletişimci olma özelliklerine sahip olduklarını belirtmiştir. Yapılan ileri analizde ise; liderlik özelliğine sahip olduğunu ifade eden öğrencilerin daha yüksek

\section{Kaynaklar}

1. Küçük O. Girişimcilik ve Küçük Işletme Yönetimi, 7. baskı, Ankara: Seçkin Yayıncılık; 2014; s. 26-30.

2. Yılmaz E, Sünbül AM. Üniversite Öğrencilerine Yönelik Girişimcilik Ölçeğinin Geliştirilmesi. Selçuk Üniversitesi Sosyal Bilimler Enstitüsü Dergisi 2009; 21:195-203.

3. Akpınar T, Küçükgöksel NÇ. Meslek Yüksekokulu Öğrencilerinin Girişimcilik Algısı ve Girişimciliği Engelleyen Sebepler. Balkan ve Yakın Doğu Sosyal Bilimler Dergisi 2015; 01:13-9.

4. Öztürk YE, Köksal O, Kıraç R. Sağlık Yönetimi Bölümü Öğrencilerine Yönelik Girişimcilik Ölçeğinin Geliştirilmesi. JHS 2014; 11:582-97.

5. Boore J, Porter S. Education for Entrepreneurship in Nursing. Nurse Educ Today 2011; 31:184-91.

6. International council of nurses(ICN). Guidelines on the Nurse Entre/Intrapreneur Providing Nursing Service. http://www. hrhresourcecenter.org/node/1150. (Erişim Tarihi: 09 Temmuz 2016). düzeyde girişimci oldukları belirlenmiştir. Literatür incelendiğinde, girişimci kişilerde farklı kişilik özellikleri görülse de, genel sonuçlar girişimci kişide bulunması gereken özelliklere sahip olmanın girişimcilik eğilimini arttırdığını göstermektedir $(15,18,21,22)$. Bu uyumlu bulgulara dayanarak; başarılı bir girişimcinin yenilikçilik, liderlik, iyi iletişim becerisi ve yaratıcılık gibi bazı kişilik özelliklerine sahip olması gerektiğini söylemek mümkündür. Bu özellikleri taşıyan bireylerin girişimcilik konusunda desteklenmesi, ülke kalkınmasında önemli rol oynanacak girişimcilerin arttırılmasına katkı sağlayacaktır.

\section{Sonuç}

Çalışma sonuçlarımıza göre, öğrencilerin girişimcilik düzeylerinin yüksek olduğu belirlenirken, iş deneyimi, ailede girişimci birinin varlığı, girişimci kişilik özelliklerine sahip olmanın girişimciliği arttırdığı bulunmuştur. Öğrencilerin girişimcilik potansiyelini kullanabilmesi ve başarılı girişimciler yetiştirmek için eğitimcilere önemli görevler düşmektedir. Bu bağlamda; girişimcilik derslerinin girişimcilik potansiyeline yönelik gizli kalmış özelliklerin ortaya çıkması ve farkındalığı geliştirecek şekilde düzenlenmesi önerilmektedir. Bu düzenleme, teorik bilginin yanında pratiğe de yer verilmesi, kurum gezilerinin organize edilmesi, derslere başarılı girişimcilerin davet edilmesi gibi etkinlikleri kapsamalıdır.

Bu araştırma tek bir merkezde yürütülmesi nedeniyle tüm Türkiye'ye genellenemez. Bu nedenle; hemşirelik öğrencilerinde girişimcilik ve girişimciliği etkileyen faktörleri incelemek için daha büyük örneklemlerde çalışmalar yapılmasını önermekteyiz. Ayrıca öğrencilerin girişimcilik kavramına ilişkin öznel bakış açılarını incelemek amacıyla niteliksel çalışmaların gerçekleştirilmesi de literatüre önemli bir katkı sağlayacaktır.

7. Arslan H, Şener DK. Hemşirelikte Yeni ve Önemli Bir Kavram: Girişimcilik. FN Hem Derg 2012; 20:140-5.

8. Roggenkamp SD, White KR. Four Nurse Entrepreneurs: What Motivated Them to Start Their Own Businesses. Health Care Manage Rev 1998; 23:67-75.

9. Elango B, Hunter GL, Wichell M. Barriers to Nurse Entrepreneurship: a Study of the Process Model of Entrepreneurship. J Am Acad Nurse Pract 2007;19: 198-204.

10. Shirey MR. An Evidence-Based Understanding of Entrepreneurship in Nursing. Clin Nurse Spec 2007; 21:234-40.

11. Salminen L, Lindberg $E$, Gustafsson $M-L$, Heinonen J, Leino-Kilpi $H$. Entrepreneurship Education in Health Care Education. http://www hindawi.com/journals/edri/2014/312810/. (Erişim Tarihi: 10 Haziran 2016).

12. Gilmartin MJ. Principles and Practices of Social Entrepreneurship for Nursing. J Nurs Educ 2013; 52: 641-4. 
13. Gemlik N, Kiraç R. Sağlık Yönetimi Öğrencilerinin Girişimcilik Özellikleri Üzerine Bir Araştırma. Kahramanmaraş Sütçü İmam Üniversitesi İktisadi ve İdari Bilimler Fakültesi Dergisi 2013; 3:163-70.

14. Pan VL, Akay C. Eğitim Fakültesi Öğrencilerinin Girişimcilik Düzeylerinin Çeşitli Değişkenler Açısından İncelenmesi. NWSAEducation Sciences 2015; 9:125-38.

15. Solmaz SA, Aksoy Ö, Şengül S, Sarışık M. Üniversite Öğrencilerinin Girişimci Kişilik Özelliklerinin Belirlenmesi: Turizm Lisans ve Ön Lisans Öğrencileri Üzerine Bir Alan Araştırması. KMÜ Sosyal ve Ekonomik Araştırmalar Dergisi 2014; 16: 41-55.

16. Roncon PF, Munhoz S. Do Nursing Students Have Entrepreuner Profile? Rev Bras Enferm 2009; 62: 695-700.

17. Doğaner M, Altunoğlu AE. Adnan Menderes Üniversitesi Nazilli İktisadi ve İdari Bilimler Fakültesi İşletme Bölümü Öğrencilerinin Girişimcilik Eğilimleri. Organizasyon ve Yönetim Bilimleri Dergisi 2010; 2:103-10.

18. Wang CK, Wong PK. Entrepreneurial Interest of University Students in Singapore. Technovation 2004;163-72.

19. Kourilsky ML, Walstad WB. Entrepreneurship and Female Youth: Knowledge, Attitudes, Gender Differences, and Educational Practices. J Bus Venturing 1998; 13:77-88.
20. Keleş HN, Özkan TK, Doğaner M, Altunoğlu AE. Önlisans Öğrencilerinin Girişimcilik Düzeylerini Belirlemeye Yönelik Bir Araştırma. Uluslararası İktisadi ve İdari İncelemeler Dergisi 2012;9:107-18.

21. Özden K, Temurlenk MS, Başar S. Girişimcilik Eğilimi: KırgızistanTürkiye Manas Üniversitesi ve Atatürk Üniversitesi Öğrencileri Üzerine Bir Araştırma. Review of Social, Economic \& Business Studies 2008; 11:1-20.

22. Şeşen H, Basım N. Demografik Faktörler ve Kişiliğin Girişimcilik Niyetine Etkisi: Spor Bilimleri Alanında Öğrenim Gören Üniversite Öğrencileri Üzerine Bir Araştırma. Ege Akademik Bakış 2012; 1:21-8.

23. Türkiye'de Girişimcilik. http://www.tusiad.org/tr/yayinlar/raporlar/ item/1880. (Erişim Tarihi: 10 Haziran 2016).

24. Can M. Veteriner Fakültesi Öğrencilerinin Girişimcilik Potansiyeli ve Eğilimlerinin Analizi: Mustafa Kemal Üniversitesi Örneği. YYU Veteriner Fakültesi Dergisi 2014; 24:81-6.

25. Uluyol O. Öğrencilerin Girişimcilik Eğilimlerinin Belirlenmesi: Gölbaşi Meslek Yüksekokulu Örneği. Adıyaman Üniversitesi Sosyal Bilimler Enstitüsü Dergisi 2013; 6:350-72.

26. Akyüz KC, Gedik T, Aydın A, Yıldırım I, Akyüz I. Orman Fakülteleri Son Sınıf Öğrencilerinin Meslek Tercihleri ve Girişimcilik Yetenekleri. Uluslararası İktisadi ve İdari İncelemeler Dergisi 2009; 20:1-14. 